\title{
Effects of progesterone and nesting materials on response prevention and extinction of avoidance in ovariectomized female rats*
}

\author{
JAMES H. REYNIERSE and LARRY BALKEMA \\ Hope College, Holland, Michigan 49423
}

\begin{abstract}
Ovariectomized female rats received either progesterone or oil injections prior to learning a simple one-way avoidance response. During a 10-min response prevention procedure, half of the animals in each group had nesting materials present, while the remaining rats did not. The availability of nesting material during response prevention hastened extinction independent of progesterone injections.
\end{abstract}

Several studies by Baum and his colleagues clearly demonstrate that response prevention procedures are more effective when additional sources of stimulation are introduced during the response prevention period. For example, Baum (1969) placed nonfearful rats in the avoidance apparatus with each experimental rat during response prevention and found that such a social facilitation procedure hastened extinction. Mechanically disrupting the rat's behavior by systematically changing its location in the apparatus (Lederhendler \& Baum, 1970), changing illumination conditions (Baum, 1972), introducing a loud buzzer (Baum \& Gordon, 1970) or presenting positive intracranial stimulation (Gordon \& Baum, 1971) during response prevention produced similar effects.

For some time now I have suggested that the behavioral activities which accompany extinction of avoidance and response prevention procedures resemble ethological displacement activities (Reynierse, 1970, 1971, ${ }^{1}$; Reynierse, Scavio, \& Ulness, 1970). Such an analysis attaches considerable significance to Baum's research as well as to both the environmental stimuli introduced during response prevention and the activities that are directed to them. Furthermore, the behavior that is expressed is considered to be appropriate for the organism's prevailing motivational state as well as for the environmental stimuli toward which it is directed. Within the framework of ethological displacement activities, the appearance of such behavior should be facilitated by the presence of both relevant external stimulation and relevant internal motivation.

Ethological disinhibition (McFarland, 1966a, b) has been proposed to account for displacement activities. According to this view, at any point in time behaviors associated with weak motivational states are potentially capable of being expressed, but in fact are being inhibited by the predominant motivation and behaviors associated with it. Conflict, thwarting, or any disruption

\footnotetext{
*We wish to thank Kris Musco and Michelle Ville'Neuve for assistance in collecting the acquisition and extinction data. Progesterone preparations were generously supplied by the Schering Corporation, Bloomfield, New Jersey.
}

of behavior produces an attention shift in which attention is diverted from the stimuli controlling behavior to new stimuli related to a weaker source of motivation. As applied to Baum's research, during response prevention the rat's attention is diverted away from the CS or other feared cues and toward the extraneous environmental stimuli, e.g., another rat, changing illumination conditions, etc., that have been systematically introduced. Methodologically, the disinhibition hypothesis suggests a behavioral rule for determining if an activity has been disinhibited. Briefly, manipulating the motivational or environmental causal factors that determine a behavior pattern should alter the intensity or duration of that behavior but not its frequency (McFarland, 1969).

Reynierse and Straw (in press) examined the implications of the displacement activity hypothesis by specifically manipulating relevant environmental and motivational factors during response prevention. Using progesterene injections in intact female rats and focusing on nest-building activities, they found that while progesterone injections significantly increased the frequency of nesting activities during response prevention, such injections did not affect rate of extinction. However, the availability of nesting materials during response prevention hastened extinction independent of any injections. Such results parallel Baum's findings and provide partial support for the displacement hypothesis, since progesterone injections increased nest-building activities during response prevention. The experiment was not, however, relevant for the disinhibition hypothesis.

The present investigation extends our earlier investigation of the effects of progesterone injections and nesting materials on the efficacy of response prevention in facilitating extinction of avoidance. Specifically, the present study used ovariectomized rather than intact female rats, attempted to establish a dose-response curve by using three magnitudes of progesterone injections, and incorporated a nonshock control group in order to test directly some implications of the disinhibition hypothesis. 


\section{METHOD}

\section{Subjects}

The Ss were 48 female adult albino Sasco rats. All rats were ovariectomized by the vendor. Maintained individually in wire cages with food and water always available, animals were assigned at random to 12 groups of 4 rats each.

\begin{abstract}
Apparatus
The apparatus consisted of a one-way box having two discriminable compartments separated by a manually operated guillotine door. Each compartment was $18 \times 4 \times 14$ in. The shock compartment was painted flat black and, during acquisition and extinction procedures, had a grid floor consisting of $1 / 8$-in. stainless steel grids spaced $5 / 8$ in. apart, center to center. During response prevention, the shock compartment had a wooden floor painted flat black. Shock of $1.0 \mathrm{~mA}$ was delivered to the grids by a Grason-Stadler shock scrambler, Model E1064GS. The nonshock compartment was painted white and had a wooden floor. A 60-dB transistorized buzzer and the raising of the guillotine door served as the CS. A speaker mounted on the Plexiglas top of the shock compartment delivered the auditory CS directly to the shock compartment. For those rats that had nesting material available during response prevention, 40 strips of $1 / 4 \times 5$ in. fresh paper toweling were placed in the middle of the shock compartment.
\end{abstract}

\section{Procedure}

Each rat was initially injected with either progesterone or sesame oil for 10 consecutive days prior to receiving escape-avoidance training on the following day. Daily progesterone injections consisted of either 10,5 , or $2 \mathrm{mg}$ Proluton in $.2 \mathrm{cc}$ sesame oil. Oil control groups received $.2 \mathrm{cc}$ sesame oil and controlled for frequency of injections, volume and the oil vehicle.

During escape avoidance learning, acquisition conditions were identical for all animals in all experimental groups. The intertrial interval was fixed at $120 \mathrm{sec}$ with confinement in the nonshock compartment for $100 \mathrm{sec}$ and confinement in the shock compartment for $20 \mathrm{sec}$ of this interval. The CS-US interval was $5 \mathrm{sec}$, both CS and US being response terminated. All rats ran initially to an acquisition criterion of two successive avoidances.

Following achievement of the acquisition conditions, all rats received $10 \mathrm{~min}$ of response prevention. Response prevention consisted of placing the rat in the shock box for $10 \mathrm{~min}$ during which the guillotine door was closed so that $S$ could not escape or termina te the continuously present buzzer CS. Half of the rats in each injection condition had nesting material present in the shock compartment during response prevention while the remainder did not. Extinction was begun immediately after response prevention was terminated. Extinction was considered to be complete when the rat failed to respond to the CS for a 60 -sec period on two successive trials. When the rat did not respond to the $C S$, it remained in the shock compartment for the duration of the 120 -sec intertrial interval until the next trial was administered. If after 100 extinction trials the animal was still avoiding, extinction procedures were discontinued for that animal and a score of 100 was given.

In addition, in order to examine the disinhibition hypothesis, no shock control groups were employed in which each rat was injected with either 10,5 , or $2 \mathrm{mg}$ progesterone or oil. Although unshocked, each was yoked with a rat from the appropriate injection group receiving nesting strips during response prevention. Yoked Ss spent the same time in the apparatus during acquisition as experimental animals receiving identical nonshock box confinement, shockbox confinement, and CS exposure as the avoidance animal with which each was yoked. Unshocked, yoked animals were then placed in the shock compartment with the guillotine door closed and nesting material present, receiving $10 \mathrm{~min}$ continuous exposure to the
$\mathrm{CS}$ as during response prevention.

All rats were treated identically during acquisition and extinction and were differentiated only in regard to their initial injections and treatment during response prevention. Initial injections manipulated motivational state while the presence or absence of nesting material during response prevention manipulated relevant environmental stimuli. There are two experimental designs embedded in the various manipulations. Thus, emphasizing the acquisition and extinction procedures, the experimental design was a $4 \times 2$ factorial in which there were four levels of relevant motivation $(10,5$, or $2 \mathrm{mg}$ progesterone or oil) orthogonal to two levels of relevant stimulation during response prevention (nesting material present or absent). Emphasizing the role of ethological disinhibition, the experimental design was also a $4 \times 2$ factorial in which there were four levels of relevant motivation $(10,5$, or $2 \mathrm{mg}$ progesterone or oil) orthogonal to two levels of fear (escape-avoidance shocked rats or their unshocked yoked controls).

During response prevention, each rat was carefully observed for the entire $10-\mathrm{min}$ period. Each behavioral category was continuously recorded on an Esterline-Angus event recorder and summarized on elapsed time meters and counters. The five observed activities (standing, grooming, crouching, general activity, and nesting) represent mutually exclusive and exhaustive molar classes of behavior which were identified for recording purposes as follows: standing-any upright posture in which the rat reared up on its hindlegs; grooming-any scratching, washing, or licking of any part of the body or face; crouching-a stationary posture with the body flat or arched and with all four feet in contact with the floor; general activity-any generalized locomotor pettern within the apparatus, including continuous upper body movements in the stationary animal; the nesting-any active manipulation of the nesting material, particularly chewing, shredding, and heaping-up movements.

Finally, a crude 3-point rating scale was constructed to evaluate the qualitative aspects of the terminal "nest" following completion of the response prevention or CS exposure period. All ratings were based on the written descriptions of the nests which were routinely recorded following the completion of each ovservation session. The ratings, made independently by two judges, were made at the end of the experiment. A score of " 1 " was given if the nesting material remained undisturbed in the center of the shock compartment; a score of " 2 " was given if about half of the nesting material was undisturbed while the remainder was heaped-up in the form of crude nest; and a score of " 3 " was given if all or almost all of the nesting material was heaped-up into a pile.

\section{RESULTS}

Analysis of variance for trials to achieve the acquisition criterion was not significant, indicating that any behavioral differences could not reasonably be attributed to differential performance during acquisition. For all measures, injections were not significant either as a main effect or in interaction. Accordingly, the behavioral measures summarized in Table 1 sum across injections and prior motivational state and are restricted to the environmental conditions during response prevention including no nest strips, nest strips, and no shock yoked control conditions. Consistent with earlier findings, the main effect for relevant environmental stimulation was significant $(\mathrm{F}=$ $5.94, \mathrm{df}=1 / 24, \mathrm{p}<.05)$, as animals which had nesting material present during response prevention, 
extinguished significantly faster than those which were only exposed to the CS during this period.

Additional analyses of variance were performed on the frequency and duration of the behavioral categories observed during response prevention. Standing was significant for frequency $(\mathrm{F}=12.1, \mathrm{df}=2 / 36, \mathrm{p}<.001)$ and duration $(\mathrm{F}=7.78, \mathrm{df}=2 / 36, \mathrm{p}<.01)$. Grooming was also significant for both frequency $(\mathrm{F}=6.18, \mathrm{df}=$ $2 / 36, \mathrm{p}<.01)$ and duration $(\mathrm{F}=5.21$, df $=2 / 36$, $\mathrm{p}<.05)$. Crouching was significant only for the duration measure $(\mathrm{F}=30.79$, df $=2 / 36, \mathrm{p}<.001)$. General activity was significand for both frequency $(\mathrm{F}=5.3 \mathrm{df}=$ $2 / 36, \mathrm{p}<.01)$ and duration $(\mathrm{F}=6.67$, $\mathrm{df}=2 / 36$, $\mathrm{p}<.01)$. In each case, further analyses indicated that the no shock yoked control group was significantly different from both the nest and no nest conditions which did not differ from each other. Thus, yoked control animals exhibited higher standing, grooming, and general activity scores, but lower crouching scores during response prevention than nest and no nest conditions.

Frequency and duration of nesting activities were not significantly different. among conditions where nesting materials were present during response prevention. However, qualitative differences were reliably observed. Thus, animals that had prior escape-avoidance training tended to make heaping-up activities while no shock yoked control animals tended to restrict their activities to chewing or shredding activities. This is indirectly confirmed by the nest scores which were highly significant $(\mathrm{F}=22.09, \mathrm{df}=1 / 24, \mathrm{p}<.001)$. In the no shock yoked control groups animals tended to chew or shred only a few strips, ignoring the remainder. In contrast, previously shocked animals heaped-up the materials into the far corner away from the guillotine door, forming a crude nest there.

Compared to the amount of nesting activities observed by Reynierse \& Straw (in press), we had the distinct impression that ovariectomized rats in the present study spent considerably less time engaged in nesting activities. Since they used a modified frequency analysis with an interval base of $20 \mathrm{sec}$ in which each behavioral category received a score of either 1 or 0 during each of the 20 -sec intervals, we also examined our permanent Esterline-Angus recordings using their modified frequency analysis. Regardless of how frequently nesting appeared or continued, it received a score of 1 during each 20 -sec interval in which it appeared at least once, and a score of 0 if it did not occur. Under these scoring procedures, mean modified frequency of nesting in escape-avoidance rats was 10.94 while it was 11.87 for no-shock yoked controls. After eliminating oil controls in both conditions, the scores were 11.5 and 12.0 in nest and yoked controls, respectively. This is approximately half the level of nesting activities observed by Reynierse \& Straw (in press).
Table 1

Mean Frequency and Duration of Several Behavioral Measures Summed Across Injections Conditions

\begin{tabular}{|c|c|c|c|}
\hline Behavior Measures & Nest & $\begin{array}{c}\text { No } \\
\text { Nest }\end{array}$ & $\begin{array}{c}\text { No } \\
\text { Shock } \\
\text { Controls }\end{array}$ \\
\hline Trials to Extinction* & 34.62 & 60.88 & - \\
\hline Frequency Standing** & 25.62 & 20.25 & 45.38 \\
\hline Duration Standing** & 94.62 & 100.81 & 194.38 \\
\hline Frequency Grooming** & 6.0 & 8.62 & 12.75 \\
\hline Duration Grooming* & 37.38 & 48.88 & 98.06 \\
\hline Frequency Crouching & 41.44 & 38.38 & 53.88 \\
\hline Duration Crouching $\dagger$ & 342.81 & 419.88 & 144.69 \\
\hline Frequency General Activity** & 21.06 & 15.31 & 31.18 \\
\hline Duration General Activity** & 25.5 & 19.19 & 42.0 \\
\hline Frequency Nesting & 19.69 & - & 14.44 \\
\hline Duration Nesting & 73.81 & - & 101.25 \\
\hline Nest Score† & 2.12 & - & 1.0 \\
\hline${ }^{*} p<.05$ & & $t p<$ & .001 \\
\hline
\end{tabular}

The introduction of nesting materials during response prevention facilitated extinction, relative to conditions in which only the CS was presented. This confirms earlier research by Reynierse \& Straw (in press) and is entirely consistent with the research of Baum which indicates that response prevention procedures are facilitated and extinction is more rapid when some additional source of stimulation is introduced during the response prevention period. Interestingly, since response prevention conditions among escape-avoidance animals did not differ on such behavioral dimensions as standing, grooming, crouching, or general activity, it appears that these results are independent of a relaxation interpretation (Baum, 1970; Denny, 1971). As such, these data offer limited support for a distraction or attention shift model of the efficacy of response prevention.

The comparisons with the no shock yoked control conditions do not support the disinhibition hypotheses. Considering the low level of nesting activities, this is not particularly damaging. In view of well known estrogen priming effects upon progesterone, demonstration of the motivational role of progesterone on nesting activities as well as a more sensitive test of the disinhibition hypothesis undoubtedly requires estrogen priming in ovariectomized rats prior to progesterone injections.

\section{REFERENCES}

Baum, M. Extinction of an avoidance response motivated by intense fear; social facilitation of the action of response prevention (flooding) in rats. Behavior Research \& Therapy, $1969,7,57-62$.

Baum, M. Extinction of avoidance responding through response prevention (flooding). Psychological Bulletin, 1970, 74, 276-284.

Baum, M. Flooding (response prevention) in rats: The effects of immediate vs delayed flooding and of changed illumination conditions during flooding. Canadian Journal of Psychology, 1972, 26, 190-200.

Baum, M., \& Gordon, A. Effect of loud buzzer applied during response prevention (flooding) in rats. Behavior Research \& Therapy, 1970, 8, 287-292.

Denny, M. R. Relaxation theory and experiments. In F. R. Brush (Ed.), Aversive conditioning and learning. New York: Academ ic Press, 1971.

Gordon, A., \& Baum, M. Increased efficacy of flooding (response prevention) in rats through positive intracranial stimulation. Journal of Comparative \& Physiological Psychology, 1971, 75, 68-72.

Lederhendler, I., \& Baum, M. Mechanical facilitation of the action of response prevention (flooding) in rats. Behavior Research \& Therapy, 1970, 8, 43-48. 
McFarland, D. F. On the causal and functional significance of displacement activities. Zeitschrift für Tierp sychologie, 1966a, 23, 217-235.

McFarland, D. J. The role of attention in the disinhibition of displacement activities. Quarterly Journal of Experimental Psychology, 1966b, 18, 19-30.

McFarland, D. J. Mechanisms of behavioral disinhibition. Animal Behaviour, $1969,17,238-242$.

Reynierse, J. H. A conflict and ethological theory of extinction. Paper presented at the Psychonomic Society Meetings, San Antonio, Texas, 1970.

Reynierse, J. H. Displacement activities during psychological extinction: Empirical results and theoretical implications. Paper presented at the XIIth International Ethological Conference, Edinburgh, Scotland, 1971.
Reynierse, J. H., Scavio, M. J., \& Ulness, J. D. An ethological analysis of classically conditioned fear. In J. H. Ryenierse (Ed.), Current issues in animal learning. Lincoln: University of Nebraska Press, 1970.

Reynierse, J. H., \& Straw, M. K. Effects of progesterone and nesting materials on response prevention and extinction of avoidance in rats. Behavior Research \& Therapy, in press.

\section{NOTE}

1. Reynierse, J. H. The role of adjunct activities accompanying response prevention. In preparation.

(Received for publication March 8, 1974.) 